\title{
The Cumulative Disadvantages of Socially Toxic Family Environments: A Comparison of Early Life Experiences of Incarcerated Men and University Students
}

\author{
Joseph Michalski1* \\ ${ }^{1}$ King's University College at Western University, CANADA \\ *Corresponding Author: jmichal2@uwo.ca \\ Citation: Michalski, J. (2017). The Cumulative Disadvantages of Socially Toxic Family Environments: A \\ Comparison of Early Life Experiences of Incarcerated Men and University Students, European Journal of \\ Sociology and Anthropology, 2(2), 4. https://doi.org/10.20897/jcasc/80926
}

Published: December 28, 2017

\begin{abstract}
The paper examines the antecedents of criminal behavior through the process of retrospective family and life course histories in which incarcerated male inmates and male university students are compared. The main focus is on early childhood experiences and parental behaviors. The study data derive from intensive, face-to-face interviews with 38 men incarcerated for violent offences and a matched group of 66 men attending university at the same time. The interviews focus on the relative importance of adverse childhood experiences and linkages with adolescence. The interviews demonstrated that nearly four-fifths of the inmates experienced toxic family environments by the time they reached adolescence, as compared with only two of the university students. Qualitative analyses flesh out the major themes, experiences, and "risk factors" that helped shape the trajectories of both groups of men. The socially toxic family environments and sub-optimal parenting practices that most inmates endured produced long-term, adverse effects in reducing their capacities for resilience, forging healthy relationships with their peers, and remaining in school.
\end{abstract}

Keywords: crime, life course, toxic family lives, cumulative disadvantage

\section{INTRODUCTION}

In Lost Boys, James Garbarino presents several stories of young boys subjected to parental neglect and rejection, as well as various forms of "social toxicity" such as severe family dysfunction, extreme violence, and drug dealing. Many of the youngsters shared experiences similar to those of "Peter," who recounted his issues of parental abandonment, exposure to his mother's drug usage, and recruitment into a gang. By age twelve, Peter had been shot at on three different occasions and, the following year, had been charged with killing a teen from a rival gang. In his efforts to make sense out why vulnerable children are more likely to end up in trouble and violent, Garbarino (1999) explains that a key determinant consists of the imbalance between risk and protective factors: "The presence of only one or two risk factors does not disable a child. Rather, it is the accumulation of threats that does the damage" (p. 75).

The current paper investigates that argument further by examining the retrospective life histories of two groups of men. One group consisted of men who were serving time for violent offences in a medium-security penitentiary, while a comparison group involved men from a matched cohort who were attending a public university. In interviewing more than 100 young men, the main objective was to assess their early childhood histories, parental influences, and general life experiences with their families, peers, and schooling by the time they had reached adolescence. With respect to the inmates, the driving hypothesis stemmed from Garbarino's (1999) idea that the 
cumulative disadvantages of their early life experiences helped forge the links "in the chain of events" that led eventually to their convictions for violent offenses (p. 62).

\section{LITERATURE REVIEW}

Much research focusing on the aetiology of criminal behavior compares characteristics of offenders and nonoffenders in the quest to isolate which factors might help explain why some individuals are more likely to commit crimes than others (Agnew, 2005; Bush, Mullis and Mullis, 2000; Higgins, Piquero and Piquero, 2011; Stevenson, Hall and Innes, 2004). Various studies highlight "antisocial tendencies" such as physical aggression, oppositional behavior (e.g., disobedience), and impulsivity as directly correlated with early delinquency, substance use, and schooling problems (Moffitt, 1993; Staff et al., 2015; Tremblay, 2013). While some antisocial behavioral tendencies have an organic or neuro-psychological component, the environmental context within which young children are raised - which clearly lies well beyond their control - has an especially profound impact in terms of healthy child development (Farrington and Welsh, 2007; Maggi et al., 2010; Moffitt et al., 2011; Sullivan and Newsome, 2015).

From a sociological perspective, harsh family environments, child maltreatment, and sub-optimal parenting practices arguably help set the stage for negative outcomes in adolescence and increase the probability of adult problems. The effects of adverse childhood experiences (ACEs) include the immediacy of psychological issues and mental health problems (Vogel and Messner, 2012), a greater likelihood of engaging in juvenile delinquency (Wolff, Baglivio and Piquero, 2017), and even increased risks of death in adulthood (Felitti et al., 1998). The Centers for Disease Control and Prevention (2015) identifies the most prominent ACEs linked to disease- and accident-related mortality as including: emotional abuse, physical abuse, sexual abuse, emotional neglect, physical neglect, violence toward the mother, household substance abuse, household mental illness, parental separation or divorce, and having an incarcerated household member. Most important for the current study, the evidence indicates that the combined effects of accumulated ACEs increase the odds of a range of negative adult experiences, including exposure to violence and the prevalence of incarceration (Bellis et al., 2014).

The reasons why distal factors such as ACEs should have such long-term effects are complicated, but one facet cannot be denied: parenting matters (Boutwell and Beaver, 2010; Patt, 2010; Simons and Conger, 2007). While parents are not solely responsible for every aspect of their family circumstances, the above factors highlight the dramatic and often long-lasting effects of parenting behavior upon young children. Understanding why these various early life experiences and conditions may have such long-term impacts continues to be a critical issue among criminological researchers. One particularly fruitful avenue to help "connect the dots" has been the development and application of the life course approach (Piquero and Mazerolle, 2001).

From a life course perspective, individuals' experiences are embedded within social networks of relationships that help place them upon developmental trajectories. The most important of these commences with the family of origin, or the formative years associated with brain development, language, and a range of psychosocial characteristics, as well as the social conditions associated with bonding, security, and trust. Parents and caregivers assume a critical role in healthy child development, which can be undermined if young children are exposed to noxious stimuli repeatedly and the ACEs accumulate over time. Such toxic environments can affect the immediate well-being of children, but also may set them upon primary trajectories toward delinquency and criminality without sufficient protective factors or social supports (Minh et al., 2013; Sampson and Laub, 1992, 1993; see Elder, 1985).

Human interactions across a range of contexts lead to key transitions that can alter the prevailing trajectories. These more immediate and encompassing life events often signal a shift toward a new stage of the life course. The transitions are delineated by specific events, such as graduations, employment, living on one's own or separate from one's family, first marriages, or becoming a parent. Some transitions are age-graded and predictable, but all are conditioned by the historical period in which individual lives are situated. Most important, these transitions are embedded in networks of social relationships across the life span. The dynamic interplay of individual and social contexts - and interlocking trajectories and transitions - can produce turning points or significant changes over the life course (Carlsson, 2012).

While trajectories facilitate an understanding of the connection between childhood events and adulthood experiences, countervailing forces may yet redirect individual pathways. On the one hand, former juvenile delinquents are at greater risk for criminal behavior in adulthood. The most potent early risk factors from the literature include chronic poverty (Hutchison, 2009), parental drug involvement or alcoholism (Widom and White, 1997), child maltreatment (Topitzes et al., 2011), persistent familial violence (Park, Smith and Ireland, 2012), parental incarceration (Aaron and Dallaire, 2010), and family instability or dissolution (Kierkus and Baer, 2003). The combination of factors compounds the difficulties children must confront, establishing high-risk trajectories toward problem behaviors and delinquency. Children raised in such environments are likely over time to witness the intensification of these initial disadvantages through negative peer associations and routine rejections in mainstream institutional spheres such as schools. 
On the other hand, large numbers of former delinquents are not arrested or involved any longer in criminal behavior. While some argue that such desistance from crime reflects a natural function of age-graded behavior, others suggest life course transitions that provide stability and promote social ties have more powerful effects (Rocque, 2015). Sampson and Laub (1993), for instance, argue that social ties embedded in adult transitions such as marital attachment, job stability, or military service explain variations in criminal behavior unaccounted for by childhood delinquency. By the same token, Laub and Sampson (2003) note that "most offenders desist in response to structurally induced turning points that serve as the catalyst for sustaining long term behavioral change" (p. 147).

Sampson and Laub (1997) use the concept of "cumulative disadvantage" to describe a weakening of social bonds with positive role models and conventional institutions that may occur as a result of delinquent involvement. Youngsters in trouble with the law may experience a downward spiral on paths that continue to draw them away from accruing the social capital necessary to help support non-criminal lifestyles (Hoffman and Dufur, 2008; cf. Bernburg, Krohn and Rivera, 2006). Some of the research has focused on individual traits and behaviors that may compromise the formation of supportive social bonds, such as aggression and substance use (Ford, 2005). By the same logic, countervailing forces such as educational achievement and community involvement can serve as turning points to facilitate the reintegration of former delinquents (Ford and Schroeder, 2011; Blomberg, Bales and Piquero, 2012; Fox, 2016).

From the earliest life stages, children with developmental and family risk factors can be expected to embark upon antisocial and delinquent pathways by adolescence (Staff et al., 2015). These patterns typically receive reinforcement through peer associations. As Hawdon (2004) has shown, peer influences or one's circle of friends can be especially significant factors linked to substance use and delinquent behaviors. Drawing on longitudinal data from the Family Lifestyles Project, Garnier and Stein (2002) conclude that their research "demonstrates the simultaneous effects of both family and peer domains on problem behaviors and the relationships between early family environment and peer experiences that predict adolescent problem behavior" (p. 53). Piquero et al. (2012) use data from the Cambridge Study in Delinquent Development to argue that early-life risk factors matter in predicting long-term criminal outcomes and even life failure, although different offending trajectories must be considered as well.

\section{SOCIALLY TOXIC ENVIRONMENTS}

Building upon such logic and evidence, the current work operates from the premise that infants are born into diverse environments that confer distinct advantages and disadvantages with respect to healthy child development (Maggi et al., 2010). The research in the past two decades has confirmed the importance of establishing supportive environments conducive to brain development and learning opportunities (Pennsylvania Partnerships for Children, 1998; Young, 2015). The home environment, including the range of parenting behaviors and practices, directly affects the likelihood of children developing behavioral problems or, conversely, of protecting children against adverse outcomes (Evans, Li and Whipple, 2013; Fanti and Henrich, 2010; Laurens et al., 2017; Mendel, Tomasello and Nochajski, 2012). To help elaborate further on these variable situations, the concept of "socially toxic environments" refers to the constellations of harsh living conditions that place individuals at significant risk for developmental problems.

Garbarino (1995) used the term originally to describe the contemporary social world of children or "the social context in which they grow up," which he argued "has become poisonous to their development" (p. 4). The social toxicity to which Garbarino referred consists of an amalgam of sociocultural factors such as violence, poverty, disruptive relationships, depression, alienation, and despair. A socially toxic environment refers to any "forces in the land that pollute the environment of children and youth" (p. 5). Moreover, as environmental toxicity increases, young people's coping capacities are weakened; their vulnerability predisposes them to greater risks for developmental problems, adverse health effects, and negative behavioral outcomes.

The thesis here suggests that cumulative disadvantage increases over time via exposure to the external risk factors that predominate in the early years (Klevens et al., 2001). The family of origin is the critical nexus within which youngsters learn through direct observation, as well as internalize cultural scripts that reinforce maladaptive behaviors and may reduce the probability of establishing stable, non-criminal relationships (Bandura, 1977; Cairns and Cairns, 1994; Foster and Hagan, 2007; Gilgun, 1996). Sabates and Dex (2015) explain that "early exposure to multiple risks in childhood has cumulative effects throughout the life course" (p. 95). Similarly, Reavis et al. (2013) determined that adult criminals report having experienced far more adverse childhood events than an adult male comparison group.

This paper explores these issues to assess the relative effects of early childhood exposure to risk factors hypothesized to be associated with violent criminal behavior in adulthood. The main thesis suggests that no single factor alone always or necessarily increases the probability of violent criminal offending. Rather, as Klevens et al. 
(2001) have shown, varying combinations of risk factors exacerbate cumulative disadvantages that are linked to the long-term propensity for violent criminal outcomes. The study examines retroactively the extent to which combinations of risk factors produce socially toxic family environments and serve as distal precursors to violent criminality in adulthood (see Murray, et al., 2010).

\section{METHODOLOGY}

Consistent with Holligan and Deuchar's (2015) approach and Klevens et al.'s (2001) case control method, life history interviews were conducted first with 38 male inmates imprisoned for violent offenses. Mostly in their midtwenties, these men were serving sentences generally of 40 months or longer in a medium-security federal correctional facility located in southern Ontario. In addition, a matched comparison group of 66 males enrolled in an Ontario university were interviewed using the same core instrument. By their early twenties, the latter group was enrolled in university and largely uninvolved with violent or other criminal forms of behavior. While by no means an experimental design, both groups of young men were of similar age and the same cohort to control to some degree for historical conditions (Elder, Johnson and Crosnoe, 2003).

\section{Recruitment and Samples}

The first sample consisted of self-selected inmates from a facility where a research assistant worked as a Correctional Officer. She had an established rapport with many of the inmates on one unit, several of whom readily volunteered for the interviews. The recruitment from that unit involved a simple posting that promised coffee and doughnuts in exchange for a roughly two-hour break from the inmates' regular routines to talk about their life histories. The inmates could choose to be interviewed by either the author or the research assistant, depending on their comfort level. Nearly half the inmates on the unit volunteered to participate. Their demographic and offending profiles matched those of the whole unit, with no significant differences in terms of average age, length of sentence, or offence types.

Most inmates were serving time for multiple offences and had received sentences from 3-10 years. Table 1 contains the distribution by each inmate's "main" offence. In all but one case, the men were serving time currently for violent crimes, either alone or in conjunction with property offences. Most men acknowledged readily their participation in the crimes for which they were charged. In five cases, the inmates held different views than the official police accounts, believing that they were less involved or had assumed some responsibility for the actions of others. Two inmates were appealing their convictions. ${ }^{1}$

Table 1. Offence Categories of Most Serious Offences

\begin{tabular}{lc}
\hline Primary Offence (Severity) & Cases \\
\hline Murder or manslaughter & 11 \\
\hline Aggravated assault or attempted murder & 9 \\
\hline Armed robbery (money motive with some violence) & 17 \\
\hline Property offences only & 1 \\
\hline Total & 38 \\
\hline
\end{tabular}

The second group consisted of university students attending a public university at the same time as their incarcerated counterparts. These individuals were born in roughly the same years or as part of the same generational cohort as the inmates (with a few slightly older inmates). Students were recruited through an on-campus campaign aimed at undergraduate criminology and sociology students. The volunteers agreed to participate without any incentives or knowledge that inmates had been interviewed using the same life history approach, but signed consent forms to participate, consistent with the requirements of the university's ethics review committee. The original aim was to interview a comparable number of university students. The initial sample, however, produced such low rates of early childhood traumas that the author initiated a second round of interviewing to increase sample heterogeneity. Thus 66 male students participated as a complement to the 38 inmates, or an overall sample of 104 interviewees.

\section{Interview Schedules}

The interviews assessed the relative importance of their background characteristics, family life, friendship networks, and schooling at selected developmental stages, as well as life-course transitions, in shaping their pathways into either of two public institutions: the medium-security prison or the university. The interviewees

\footnotetext{
${ }^{1}$ In one specific case, the inmate vehemently denied having been involved in the murder for which he was convicted, although he was not appealing the court's decision.
} 
responded to questions dealing with key issues at three specific points: 1) as young children around the age of five; 2) as adolescents entering puberty; and 3) as teens during their high school years. For each life stage, participants were asked about their families and relationships with their parents, living conditions (including housing stability), general social and economic situations, friendship networks, supportive and non-supportive parenting practices, the use of corporal punishment, and parental substance use.

Many questions were repeated for the next two stages, but then supplemented with additional items pertaining to their schooling, romantic involvements, and work experiences. The interviews included open-ended questions about the circumstances under which they first left home, along with critical events or turning points that they believed help shape their lives as teenagers and young adults. A final section gathered information about the circumstances surrounding the most recent crimes for which the inmates had been incarcerated, while the university students were asked about their decisions to attend higher education.

The interviewers recorded the responses manually for each question posed. While many questions dealt with highly specific information, several open-ended questions dealt with life experiences that required lengthier transcriptions. The quotes were recorded verbatim in quotation marks or, in more expansive accounts, as summary descriptions in note form. For the inmate interviews, the author reviewed case file data to confirm key information or reports of early life experiences, family histories, and schooling. Inmates rarely contradicted the case file materials, with discrepancies usually linked to the circumstances surrounding their convictions. The face-to-face interviews with the inmates averaged just over two hours.

The author alone interviewed the university students, which usually required between 60-90 minutes. Their responses were not corroborated further, but most items did not involve highly sensitive information beyond certain kinds of personal disclosures (e.g., drug use) and the usual concerns regarding the possibility of social desirability bias with self-reports. In accordance with best practices, the interviews occurred only after subjects reviewed a study information guide and signed a consent form ensuring confidentiality. All interviews were conducted: a) in private and were not tape-recorded (the manual recording of responses was done with the consent of the interviewees); b) naturalistically and supportively, as more of a conversation; and c) without any pressure to respond or making evaluative judgments about the content of their responses (Tourangeau and Yan, 2007). In fact, nearly every respondent, whether an inmate or a university student, visibly appeared to enjoy the interviews and telling their "life stories." 2

\section{Analytic Strategy}

The author transcribed the interviews to create an integrated file of life stage information to summarize key demographic information along with family, friendship, schooling, and employment data. The next stage involved axial coding of the more detailed accounts of life experiences, using highlighted "sticky notes" for each transcript. The analysis identified the key themes and experiences that participants discussed during their interviews, broken down section by section. The main analytic focus involved the identification of important social context issues and the social networks within which the interviewees were embedded at life stages where the developmental transitions occurred (see above). The current study focuses mainly on their early life stage experiences, or the prevalence and comorbidity of several risk factors associated with troubled lives and antisocial behaviors prior to adolescence.

A final pass through the data had two objectives. The first aim consisted of categorizing each of the themes based on the literal translation of the words used and the main ideas that interviewees hoped to convey in responding to direct questions. Several questions inquired about their most vivid memories at various stages of their lives, while highly specific questions focused on both "risk" factors (e.g., "When you were growing up, did you ever see your parents or step-parents be physically violent toward one another in any way?") and "protective" factors (e.g., "When you were a young child, how often would you say your parent(s) read to you?"). Accompanying probes allowed for the interviewees to fill in the details about what they recalled happening, as well as how often parents (or others) engaged in a variety of different forms of prosocial and harmful behaviors alike.

The second objective involved simply descriptive counts of how often the interviewees identified each specific behavioral pattern (positive and negative), along with the degree to which different patterns clustered together thematically. Since neither sample involved probability sampling, formal tests of statistical significance could not be used with any confidence to generalize these results beyond the samples in hand. Hence the focus of the current analysis centers more around the overall narratives that could be constructed based on the responses and language each person used in describing their lives in early childhood and then upon entry into puberty and adolescence.

\footnotetext{
2 The inmates were remarkably responsive and engaged for the most part, since the interviews provided a break from their normal routines and they were able to enjoy the benefits of outside food and company in a relaxed setting. Most prisoners talked, as with their student counterparts, quite extensively and even at times effusively about their life histories. It is not an everyday experience for people to have an active, non-judgmental listener interested in hearing all about their lives.
} 


\section{Study Limitations}

The study's limitations are linked to the methodology and the exploratory nature of the study based on in-depth life history interviews. While the author developed a purposive, matched sample of inmates and university students, neither could be designated as representative of their more general populations. Hence the author eschewed formal tests of statistical significance as a key method for determining similarities or differences between the two groups, even where descriptive summary statistics were presented. The non-random samples ensure further that the findings cannot necessarily be generalized to the experiences of all types of inmates or those attending higher education. The exclusive focus on male experiences, moreover, precludes any discussion or generalizations about females or transgender individuals. Future research plans include replicating the same study approach with incarcerated females and a matched group (demographically) of women attending universities.

The cross-sectional and retrospective nature of the interviews limits any definitive means of establishing causality, which helps explain the study's focus on the more thematic nature of the memories and recollections of their early family lives and significant life events. Individual reconstructions of their lived experiences are fraught with problems (e.g., selective memory, accuracy), but these were minimized as much as possible by asking quite specific questions in a consistent fashion for each of three distinct time periods and structured as a life history (Klevens et al., 2001). The inmate interviews were supplemented further with cross-referencing to case file information to ensure greater accuracy. But even if the details were not always entirely accurate, the richness of the data revealed a consistent set of overarching themes and "languages" that the inmates and students used to construct their life histories. As a simple example, many of the students used the word "love" at various points along the way during the interviews to describe different facets of their family lives or their childhood memories (e.g., "I loved hanging out with my brother"), but the inmates almost never used the term in their conversations.

\section{STUDY FINDINGS}

\section{Demographic Characteristics}

In terms of their backgrounds and basic demographic information, the inmates ranged in age from 20-66 (mostly in their 20s and early 30s, with one older man), with a mean age of 27 and a median of 25 years. The university students ranged from 19-52, with a mean of 24 and a median of 23 years. Clear majorities of both groups grew up in either towns or mid-sized urban centers. The geographic distributions were comparable, with similar Ontario school systems and educational opportunities for both subgroups. ${ }^{3}$

Nearly all inmates reported coming from either middle-class or working-class families; four lived in poverty and an equal number grew up in upper middle-class or wealthy families. By comparison, the university students were more likely to hail from upper middle-class or wealthy families (just under 32\%) and less likely to have lived in poverty (4.5\%). No one in either group reported being "homeless" at any point, although at least two inmates reported having to move because their family could not pay the rent (two others reported being "not sure").

Most men in both groups grew up in houses owned by their parents, although a higher proportion of the university students' parents owned their own homes. Approximately half of both groups reported moving at least once by age five, with no dominant reason or pattern emerging. The economic factor, however, played a less prominent role with respect to the long-term outcomes, especially as one drills down further into their lives to assess the salient family dynamics. The remainder of the paper focuses on the thematic analysis of early childhood risk factors and pivotal family experiences as these relate to subsequent institutional outcomes.

\section{Independent Risk Factors}

Both the inmates and the university students overall were remarkably open to discussing their life histories, whether in talking about positive experiences or in recalling some of their more difficult memories. Their stories reflected a genuine interest in trying to reconstruct their pasts, as well as appeared to have some therapeutic value as interviewees divulged intimate details of their early family lives and certain challenges they confronted. In terms of possible adverse childhood events, the thematic analysis revealed that six factors recurred most frequently, each identified in the literature as a potential risk factor for adult criminality:

- Parental daily drinking or alcoholism (Reavis et al., 2013)

- Parental drug use or addiction (Widom, Schuck and White, 2006)

- Parental involvement in criminal activities (Laurens et al., 2017)

\footnotetext{
${ }^{3}$ It is important to note that in this study, most interviewees did not grow up in impoverished urban cores or American-style "ghettos." While the educational institutions were by no means uniform across geographic regions, neither did the interviewees experience dramatic fluctuations in the quality of their public schooling, as most grew up in southern Ontario and without much inequality with respect to funding and resources for the public school system.
} 
- Persistent family violence or routine spousal conflict (Ireland and Smith, 2009)

- Child maltreatment, i.e., physical and emotional abuse; neglect (Payne et al., 2005)

- Family instability, i.e., divorce, child protection, foster care (Yampolskaya et al., 2011)

In considering these risk factors, the fact that each directly implicates parental behavior represents a common thread that weaves them together. The inmates indicated they were far more likely to have experienced all but one of the risk factors as compared with the university students during their early childhoods. The lone exception involved daily drinking or alcoholism, even though a slightly higher percentage of inmates reported witnessing more of that behavior too from their parents or caregivers. Thus the inmates in their young lives confronted much higher prospects of having parents who used illicit drugs, engaged in more intimate partner violence, were more likely to separate or divorce, or used of child protective services. The inmates also reported a higher incidence of child maltreatment, especially in terms of child neglect or lack of parental involvement in caregiving (e.g., less likely to have a parent read to them). Table 2 presents the relative distributions of the presence of each factor in the early lives of the inmates and students.

Table 2. Parental Behaviors by Age Five for Inmates and Students

\begin{tabular}{lcc}
\hline Parental Behaviors & $\begin{array}{c}\text { \% Inmates } \\
(\mathbf{n}=\mathbf{3 8})\end{array}$ & $\begin{array}{c}\text { \% Students } \\
(\mathbf{n}=\mathbf{6 6})\end{array}$ \\
\hline Daily drinking or alcoholism & 57.9 & 45.5 \\
\hline Drug use or addiction & 44.7 & 6.1 \\
\hline Criminal involvement & 21.1 & 4.5 \\
\hline Family violence/spousal conflict & 76.3 & 16.7 \\
\hline Child maltreatment & 57.9 & 13.7 \\
\hline Family instability & 47.4 & 12.1 \\
\hline
\end{tabular}

None of these factors alone determined long-term institutional outcomes, but the multiple risk factors created the types of toxic family environments that appeared to have an enduring impact. For example, one inmate was born to two teenaged parents who divorced by the time he was two. He then lived with his father and a stepmother who was physically abusive. He stated that "the only thing that prevented me from using the shotgun on my stepmother as a young child was the fact that I couldn't reach the weapon." His father beat him severely as well for his more serious transgressions, and, following one especially harsh beating, child protective services removed him from the home. In another case, an inmate stated his parents would tie him up in a harness on the front porch "while they went to party and to get more drugs." He witnessed much domestic violence, including one incident where his father beat his mother savagely with a coat hanger - the one on which he reportedly "hung my little jacket." Both parents eventually were arrested for heroin and drug trafficking. The boy ended up being raised by his grandmother, lost contact with his father, and yet continued to visit his mother in prison for several years.

The inmates frequently described their family lives with colloquial language that alluded to social toxicity. One inmate, for instance, responded immediately to the question about his earliest memories by stating his family was "fucked up" and how he "watched my dad beat the shit out of my mom." He talked further about how "there was a lot of dope around" and summarized his situation with the comment that "my family is dysfunctional hardcore." After his parents split up, his mother started seeing another man who "beat the shit out of my baby sister; she was almost killed." In another equally dramatic case, an inmate described how he did not really know his father, who was sent to jail before he had turned three years old for drugs and related offenses. His mother, who worked as a nurse, then "hooked up with this guy" after they had moved and "he was violent with my mom and always on cocaine." He then described the traumatizing impact of his most vivid memory:

Her boyfriend came home late. He went into the bedroom and yelled at my sister and mom, asked sister "who is your mom fucking?" He threw my sister around, took mom in front of stove, grabbed a knife and stabbed her. He took a lot of swings, but only got her 3 or 4 times. Mom hunched over and he was squeezing her blood out of her. I stood by shaking, watching it all. He got arrested and she was hospitalized... She didn't have a man in her life for the next three years, but I was always looking over my shoulder fearing the man who stabbed my mom.

These examples reflect some of the most powerful correlates of long-term violence and criminal activities. The trajectories linked to early life experiences proved particularly forceful. By the time those living in toxic environments entered public schools, the lack of appropriate nurturing and the general familial dysfunction created enormous barriers for these youngsters for developing healthy attachments or "non-criminal" lifestyles. The results indicate that several risk factors converged to create "toxic environments" among most of the inmates studied, yet only rarely coalesced to such dramatic negative effect within the university student families. 
For instance, parental drug use or addiction occurred in almost $45 \%$ of inmates' families, but in proportionately far fewer university student families $(6.1 \%)$. Not only were some inmates' parents addicted or even arrested for consumption or dealing, but in at least two cases the parents introduced the children to the drugs as well. Yet only four university students reported knowledge of their parents ever using illicit drugs, which usually involved marijuana. In one student's case, he reported that his father used marijuana on occasion "as a means of enhancing his professional work," or to be more "creative" in his thinking. The young man viewed his father's use of drugs as amusing rather than problematic, reporting no negative impacts. In comparison, inmates often experienced far more adverse events because of their parents' illicit drug use or alcoholism.

In addition, a much higher proportion of inmates witnessed and/or experienced persistent forms of domestic violence during their childhoods: three-fourths reported serious levels of family conflict and violence. Among university students, only one in six reported witnessing serious family violence as young children, but never to the point of police intervention. For example, consider a case of an inmate who reported that his father often acted in violent ways toward his common-law partner (the inmate's mother). He noted that his father was violent with the entire family. He reported that his younger sibling was "molested and beaten by my father," and that the worst thing that his father ever did to him as a child was to "(shove) a knife up my ass." He was removed from his home following the sexual and physical abuse, and thereafter lived in a series of foster care and group homes. That fate - direct child services intervention, foster care, and/or group home alternatives - befell almost half of the 38 inmates interviewed by the time they had reached adolescence, but only one of the university students.

The university students reported having fewer serious problems and arguably exhibited more resiliency in confronting challenges, especially through relationships with their parents. For instance, one young man had serious problems with a teacher at school and skipped classes often, but his parents sided with him and pushed for the school to transfer him to another classroom. His truancy problems abated as a result and his grades improved dramatically the following year. The general view of these young men was not that their parents were without flaws, but that they displayed more involvement in their lives. University students' parents employed authoritative parenting practices that created a healthier family environment far more regularly as compared with their imprisoned counterparts. Even among the five cases where the students were born to teenagers, the young parents offered enough resources and supports to help protect their children from any serious negative consequences.

Indeed, more than $90 \%$ of the university students indicated that their primary caregivers looked after them very well or their care "could not have been better" (two-thirds agreed with the latter statement). Perhaps equally significant, the university students reported being looked after by the same caregivers consistently; only four talked about instability or a dramatic change in terms of who looked after them. In addition, whereas $88 \%$ indicated that their parent(s) "paid a fair bit" or "paid a lot" of attention to their needs, only one respondent claimed that his main caregiver "paid no attention" to his needs. Finally, more than three in four university students stated that their parents or caregivers read to them at least once a week or more, including $31 \%$ who indicated that parental reading occurred daily as young children. These figures contrast sharply with the fewer than half of the inmates who received regular reading. In total, only $11 \%$ of the university students reported being read to "never" or "almost never" as a young child, as compared with one in three inmates.

\section{Socially Toxic Environments and Adolescence}

While any one of the aforementioned six factors might have negative developmental consequences, the various combinations of factors added layers of cumulative disadvantage that almost assuredly contributed to the adverse outcomes that ensued for the inmates. These same issues have been shown to have adverse impacts on children in the comparative research (e.g., Farrington, Ttofi and Piquero, 2016; Maldonado-Molina, et al., 2009). For example, exposure to many of the same factors were parallel predictors in a study of adult male criminality in Colombia (Klevens et al., 2001). More important, that same study confirmed that the odds ratios for criminality jumped dramatically - by a factor of more than eight - among those who reported any combination of at least three or more of the risk factors.

Hence for the present study, if interviewees reported experiencing any combination of at least three of these six dimensions before age five, then they were classified as having lived their formative years in a relatively dysfunctional or "toxic family environment." In total, $63 \%$ of the inmates provided details of their early lives, confirmed with supplementary case file information, to warrant classification in toxic situations before the age of five. The data revealed further that multiple factors typically did not converge among the university students: only two students ever experienced the same degree of toxicity during their entire childhoods. The interviews confirmed that most had to cope with far more circumscribed levels of toxicity that left them less traumatized or "at risk" compared to their incarcerated counterparts.

In total, 30 of the 38 inmates interviewed $(78.9 \%)$ experienced a high level of toxicity in their family environments if not from early childhood, then at least by the time that they reached adolescence. Yet despite the overwhelming evidence of toxic family environments, most inmates recounted some positive experiences or 
memories with their parents or caregivers. For example, the same inmate who had been removed due to sexual and physical abuse reported having some happy memories of his family life as a young child. His most vivid memories involved family fishing outings and enjoying trips to a summer cottage. Many inmates recalled at least some periods of calm and even joy, interspersed with the stormier times that they endured. In only a handful of cases did they refuse to acknowledge any such positive experiences or contentment with some aspects of their early family lives. For most inmates, however, the broader themes of their childhoods revolved around daily drinking or alcoholism, a parent's drug habits or other involvement in criminal activities, familial violence and abuse, and in many cases family breakdowns and an early introduction to strangers' homes and state institutions.

In stark contrast, a majority of university students reported having positive experiences and connections with their families dating back to their earliest memories. One student recalled that "we spent a lot of time together. We went on trips almost every couple of weeks." In primary school as well, he talked about "the attention I got from the teachers." Yet the notion of idyllic family lives even among the university students could not always be sustained, for many reported having various struggles as well.

One first-year student talked about how "money was tight in our family. My parents argued a lot, and my brother was sick." His first encounter with the law involved public drinking while underage, but he did not continue down the path toward long-term criminality. Instead, he talked about spending "a lot of time with friends and my brother playing sports" and fondly reported "I was very close with my parents." The theme of relatively strong family bonds resonated with many of the university students, but especially among those who claimed to have never been in trouble with the law:

My family was close knit. Everyone was treated equally timewise. And everyone participated in sports, organizations and clubs and we were encouraged to do so. It was cool too because my parents liked my friends and their positive attitudes. My parents often knew their parents.

Since nearly four in five inmates reported severe family difficulties before they had reached adolescence, it is probably secondary to consider what impact the parental discipline may have had. The debate persists as to whether corporal punishment has negative behavioral and emotional consequences on children, but the toxic environments to which these inmates were exposed likely overwhelmed any possible independent effect of that disciplinary tactic. It should be noted, though, that $90 \%$ of the inmates (34 of 38) reported corporal punishment by a primary caregiver as a means of being disciplined on an occasional or regular basis. Anyone witnessing serious violence in their homes or who had parents with substance abuse problems experienced corporal punishment. Hence the use of corporal punishment to discipline children cannot be disentangled easily from the other behavioral patterns established in these family households.

Furthermore, as young children, the university students' parents clearly set boundaries and disciplined them on occasion - even to the point of using corporal punishment and/or yelling to convey their displeasure in nearly $85 \%$ of the cases. Stated differently, only 10 of the 66 university students grew up in families where the main form of discipline consisted of parents only talking calmly and/or possibly giving "time outs" for misbehavior. Yet just three students reported experiencing some type of severe physical abuse in the form of choking or serious violence at the hands of their caregivers. The interviewees nevertheless reported some negative incidents or traumas that they experienced in their young lives, but tended to frame these as much more time-limited memories of specific events as opposed to lingering or persistent dramas that played out over extended periods of their childhoods.

From the life-course perspective, children have little power or choice regarding their families of origin and living situations. The inmates responded to the toxic family environments in which most had been born or raised often by externalizing their behaviors through aggression. As children, they learned to be fighters and survivors. But such "adaptive" strategies tended to further compromise successful long-term adjustment or integration into mainstream society. Their aggressive responses to circumstances might evoke responses from others, thereby reinforcing the behaviors to the detriment of the child. As Sampson and Laub (2003) argued, "aggression and conduct disorder often generate immediate and harsh responses by varying segments of society... aggression tends to foster physical counterattacks, teacher and peer rejection, punitive discipline, and harsh criminal justice sanctions" (pp. 154-5).

Perhaps such behaviors are widespread, as part of the maturation process associated with child development. The evidence suggests, though, that by the time both groups had reached adolescence, a higher percentage of the inmates were involved more often in violence, drug and alcohol use, theft, and breaking the law. One in three university students reported experimenting with drugs and alcohol upon entering their teen years, but only $12 \%$ participated in regular theft and $13.6 \%$ reported getting into fistfights "on a fairly regular basis," as well as getting "into trouble with the law" (though not always the same person). In contrast, while exact figures vary, a clear majority of inmates reported using controlled substances, engaging in theft, fighting, or breaking the law. Yet many of these individuals expressed some rather interesting insights in connecting their early life experiences with their own troubling behavioral patterns. 
While some individuals arguably were born with personality traits or characteristics that might be viewed as maladaptive to a degree, the inmates immersed from an early age in toxic family environments learned to act out with various forms of aggression. As one inmate explained, "I wish my mother hadn't been so irresponsible. If you injure a child psychologically, mentally and physically, they'll respond in a certain way." Although maladaptive or antisocial by conventional standards, the aggression and conduct disorders displayed by most inmates were typically reinforced through their interactions both within the family (many reported serious sibling fighting as well) and with their peers. Or, as another inmate reported, "after constantly witnessing and experiencing abuse, you develop a 'fuck it' attitude." That attitude, if reflected in behaviors, undermines one's chance for success. As Sampson and Laub (2003) argue, "The cumulative continuity of disadvantage is thus not only a result of stable individual differences in criminal propensity, but a dynamic process whereby childhood antisocial behavior and adolescent delinquency foster adult crime through the severance of adult social bonds" (p. 155).

In contrast, university students who had some family difficulties did not express the same intensity and proved to have more resources and resiliency to cope effectively. In one case where there were family problems during adolescence, the young man talked his parents' challenges for a two-year period when "dad was drunk and (they) were fighting about money (and he) slapped my mom and gave her a black eye." The situation spiralled downward because "my parents got into financial trouble and we had to move to a smaller house. My dad drank a lot more but (we were) still taken care of great. But that all passed when I was about 13 or 14 and went back to normal." Rather than continue to fall apart, he talked about how his parents reconciled, stated that "family life was great," and described his high school years as "perfect," especially because he had a "best friend" and experienced considerable success with sports.

Consider further one of only two cases of university students reared in a toxic family by the current study's standards. The young man grew up in a large family with an alcoholic parent, spousal violence, multiple forms of child maltreatment, and considerable sibling violence. He displayed aggression and behavioral problems in school, but received substantial positive feedback and external supports through his exceptional scholastic achievements and his athletic prowess. As an adolescent, he flirted with drugs and alcohol and becoming more involved with "the wrong crowd" (in his words), but turned his life around rather dramatically in grade 8:

I spent a great deal of time away from home because I had a pretty dysfunctional family. I honestly didn't enjoy being around my parents, who were fighting constantly, and especially my father, who always drank at night, cursed, and just always seemed miserable. But he managed to get up and go to work every day... I found my own way, with lots of teachers encouraging me and treating me with respect and interest. In addition, I had a coach, Mr. S., who really thought I was special. He pushed me to remain in sports and encouraged me throughout high school. But more than anything, I had one grade school teacher who I stayed connected to (and) they almost became like a second family. She never gave up on me, right through the worst periods with my own family and in high school. I often spent time having dinner or studying at their home in the evening rather than at my place. I look back now and realize how lucky I was to have all these people in my corner, and especially after my parents divorced while I was in high school. I could have easily ended up on drugs or in jail.

The above example represents an exceptional circumstance among the university students, i.e., an unusual case where the young man experienced much of the toxicity that most inmates reported. Yet as with the participants from Werner's (2005) Kauai longitudinal study, the student survived and even thrived in a rather difficult environment by having unconditional love and support from a caregiver outside of his family: "Children who succeeded against the odds had the opportunity to establish, early on, a close bond with at least one competent, emotionally stable person who was sensitive to their needs." She reports further that "Much of this nurturing came from substitute caregivers... Resilient children seemed to be especially adept at 'recruiting' such surrogate parents" (p. 12). In brief, having that one special person in their lives can enhance children's resiliency far beyond what might be expected. As per the above example, having a surrogate parent or family with well-adjusted, supportive individuals can be a powerful protective factor against riskier behaviors such as joining gangs.

It is difficult to assess that argument fully through retrospective interviews, but the study results are suggestive. For example, more than half the inmates $(21 / 38$ or $55 \%)$ reported joining gangs or delinquent peer groups in adolescence, as compared with only $12 \%$ of the university students. Many inmates reported that they wished they had never made that specific choice with the benefit of hindsight years later. One described it as the "worst mistake of my life," while another counselled against any young people getting involved with gangs. At the time, however, the inmates spoke of the importance of gangs in providing acceptance or even a family that they lacked in other spheres. Some felt that, in effect, the behaviors that they had learned or their adaptive responses to their toxic environments were in fact better suited to the demands of gang life and respected by fellow gang members.

Moreover, most inmates (55\%) reported having problems adapting to school in general, while fewer than one in five university students reported similar learning or emotional problems linked to their schooling. In a few cases, 
inmates identified themselves as having ADD/ADHD, dyslexia, or other reading disabilities or neuropsychological problems. Some were frustrated by frequent moves or changes of schools, their failure to be accepted by their peers, or, in at least two cases, the ridicule that they received because of being poor and not able to afford trendier clothes. As expected, some inmates reported that teachers or principals seemed to be quite hostile toward them, or perceived that authority figures were intent on harassing them at every turn.

While the causal linkages require further study, one might hypothesize that there was likely a fair degree of reciprocity in such relationships. One can imagine antisocial behaviors eliciting negative sanctions, which then reinforced the maladaptive responses and undermined whatever positive forces might have been available. As one inmate recounted, he should have been failed by a math teacher who told him directly that he passed the young man simply because he did not want to have to see him any longer. The inmate disclosed he was deeply hurt by that comment. In contrast, $80 \%$ of university students (despite mixed attitudes about school) nevertheless expressed having "strongly supportive" or "completely supportive" teachers - and some $62 \%$ reported having a "really great" teacher in their school at that time as well.

The group homes and reform schools the inmates attended did not seem to have positive impacts on these men, though again caution should be exercised with such an interpretation. The current study concentrates on only one subpopulation of inmates. By definition, the earlier state institutions failed in efforts to straighten out the lives of the men who ended up incarcerated. Some inmates reported experiencing significant levels of abuse in the group homes and alternative schools, while others stressed that their learning curve for criminal and antisocial behavior increased directly as a result of time in such institutions. While it is difficult to evaluate the merits of these claims, it seems safe to conclude that key institutions of social control contributed to the "cumulative disadvantage" of most inmates in the current sample.

In the end, only ten of 38 inmates (26.3\%) reported earning a high school diploma by age 20 , which could have been an important turning point in their lives (Bersani and Chapple, 2007). Only four of the 24 inmates born into toxic environments ever graduated from high school. Thus these inmates had significantly less education than the general population. In fact, ten of the 24 managed a maximum of grade 9 education. In contrast, six of the 14 who had at least some semblance of a non-toxic family life in their first five years managed to obtain diplomas. These figures are still far below national averages, but higher than the comparison group - almost all of whom had graduated from high school "on time."

The inmates' reasons for quitting school included a fair balance between those who were "kicked out" or "expelled," and those who felt that they were on their own and needed to make ends meet. Further schooling seemed to serve no tangible purpose. Only in retrospect did inmates report regrets that they had not continued, applied themselves more, or achieved better marks while in school. By comparison, most university student received support or even pressure to graduate high school, with nearly two-thirds remember being "expected" to attend. By the time these young men were in high school, most had the necessary supports in place and had developed a mindset focusing on university as a stepping stone to their long-term success.

\section{DISCUSSION}

Nearly $80 \%$ of inmates either were born into or endured toxic family environments by their adolescence, as compared with only two of the men attending university. The trajectories toward criminal and arguably violent dispositions were well established in most cases among these future inmates from an early age, as both witnesses and participants in highly dysfunctional families. The adaptations to the transitions encountered were almost always negative, such that nearly all turning points resulted in furthering their downward spirals. Most significant were the poor parenting practices or "aversive" parenting evident in the clear majority of inmate cases, though their parents sometimes struggled at length to help (see Nelson et al., 2006). One set of parents, for example, took out a second mortgage on their house to send their two children to private school. Most inmates even reported that their parents rated a 4 or 5 (5-point scale) in terms of expressing an interest in their schooling and supporting other aspects of their education.

But these efforts or interests were simply not sufficient to counteract the various negative forces in their children's lives, often perpetrated by the same parents who would carefully review their children's report cards. The widespread use of corporal punishment, for example, may not have been an important "cause" of subsequent delinquency and criminality, but still proved consistent with broader and largely ineffective child-rearing practices. The parents struggled often with their own social, economic, and substance problems, which in large measure created the toxic family environments that contributed to the development of weakened or maladaptive social bonds that placed these young men at risk.

The interviewees attending university clearly benefitted from more stable, healthy family environments and having parents much more highly involved in their lives from an early age. While these men encountered some problems or crises, such as having a parent who might drink too much or witnessing domestic violence, the 
multiple risk factors associated with the toxic family environments that inmate endured were far less pervasive. As one student explained, "we were far from perfect, but I'd be lying if I said my parents didn't love me or my sister, or make all kinds of sacrifices to help get us into university." Indeed, the most common refrain among the students involved the narrative that despite their family limitations, most reported that their parents supported their schooling and activities quite substantially.

The in-depth interviews and case file information confirmed that most inmates grew up in dysfunctional families with substance abuse, serious domestic violence, child abuse, and often a lack of supervision or affection. Their lives did not improve appreciably during the key transition phases, including among those who were removed from their parents' homes. The difficulties with transitions at school, as well as their predominantly negative associations with gangs or other peer groups, contributed to the cumulative disadvantage that most inmates carried with them right from the formative years of their toxic family environments.

The likelihood of these inmates desisting from criminal behavior would appear to be quite low, especially in light of their histories of long-term exposure to toxic environments, generally weak institutional supports, and a relative lack of social capital or supportive social networks within which to embed their lives. Their cumulative disadvantages yielded, for the most part, more of a survivor's mentality, which included the use of violence to achieve short-term goals. The university students not only experienced more positive parenting, but forged healthier bonds with friends and teachers in their schools, especially if their parents faltered. These men reported far less involvement with gangs, substance abuse, and delinquency as young teenagers. Their main skirmishes with the law usually involved underage drinking, but these transgressions were viewed much more as a "rite of passage" rather than a pathway to delinquency and criminality.

By the end of the interviews, while most inmates talked about their preferences for moving beyond their criminal pasts, few could identify the types of social supports or articulate concrete action plans that might facilitate a successful transition in the future. Without having established the more secure social bonds or experienced successful transitions at earlier phases in their lives, these inmates almost certainly run a high risk for re-offending. In contrast, university students managed to build up their social and human capital by navigating successfully through their teen years and graduating from high school, with reasonably strong and secure bonds to certain family members (especially parental figures), stable friendships, and even teachers from middle-school and high school whom they admired.

The study's exploratory nature does not imply a causal connection between the events and the inevitability of criminal outcomes. The thematic analysis mainly focuses on the common threads applicable to each group's alternative outcomes. The author identifies the dominant themes and common experiences that influenced the trajectories of both inmates and university students. The results highlight the importance of equifinality to suggest that there are multiple pathways to criminality and university. While not every inmate grew up in violent homes or without parents, those who experienced supportive or nurturing environments, quality parenting, and stable economic situations were the exceptions. Without interventions or vital supports at key transition stages, these men were at much greater risk for criminal involvement throughout their adolescence and into adulthood compared to the university students.

The toxic family environments that most violent offenders experienced served as the distal causes for the gradual weakening of healthy bonds and institutional supports that the men experienced. While no single factor necessarily could explain whether a young man ended up in prison or in university, the constellation of risk factors provided crucial information that might anticipate their negative, long-term behavioral consequences. Social service providers and educators with knowledge of the toxic environments might be limited in terms of their interventions, but the costs of not having effective supports in place to shift their trajectories were on full display in comparing these matched groups of young men.

Perhaps more than any other single factor, however, the study has reaffirmed the critical importance of healthy parental behaviors and responsible parenting in creating reasonably healthy and nurturing environments for their children. The constellation of risk factors that emerged clearly highlighted parenting practices, without even necessarily considering associated psychodynamic or cognitive aspects of positive parenting or parental well-being: alcoholism, drug abuse, criminal activities, domestic violence, child abuse, and family instability (among other themes). The fact that most inmates experienced varying combinations of at least three or more of these issues provided evidence of the toxic family environments and cumulative disadvantages that reinforced patterns of delinquency and criminality in the inmates' lives.

As compared with the university students, relatively few inmates could point to extended periods of "normalcy" or generally healthy, stable family environments wherein they were able to develop positive family supports and a broader sense of resiliency. Instead, they were more likely to externalize their problems through aggressive behaviors as children and later by joining gangs, engaging in various forms of delinquent behavior, sometimes retreating in substance use and abuse, and far more often by dropping out of school. In short, the toxic family environments exposed and reinforced a series of maladaptive behaviors among the inmates as youngsters, while 
failing to provide stable home lives in which young people might feel supported or be able to imagine brighter futures. The bleak alternative was captured in one inmate's response to an optimistic query as to what were his special skills or strengths in high school. The young man teared up as he responded, "Nothing, other than stealing. But I can't remember anyone ever asking me what I'm good at, so I don't know. I just never really felt I was good at anything..."

\section{REFERENCES}

Aaron, L. and Dallaire, D.H. (2010). Parental incarceration and multiple risk factors: Effects on family dynamics and children delinquency. Journal of Youth and Adolescence, 39, pp. 1471-1484. https://doi.org/10.1007/s10964009-9458-0

Agnew, R. (2005). Why do criminals offend? A general theory of crime and delinquency. Los Angeles, CA: Roxbury.

Bandura, A. (1977). Social learning theory. Englewood Cliffs, NJ: Prentice Hill.

Bellis, M.A., Lowey, H., Leckenby, N., Hughes, K. and Harrison, D. (2014). Adverse childhood experiences: Retrospective study to determine their impact on adult health behaviors and health outcomes in a UK population. Journal of Public Health, 36, pp. 81-91. https://doi.org/10.1093/pubmed/fdt038

Bernburg, J.G., Krohn, M. and Rivera, C. (2006). Official labeling, criminal embeddedness, and subsequent delinquency: A longitudinal test of labeling theory. Journal of Research in Crime and Delinquency, 43, pp. 67-88. https://doi.org/10.1177/0022427805280068

Bersani, B.E. and Chapple, C.L. (2007). School failure as an adolescent turning point. Sociological Focus, 40, pp. 370391. https://doi.org/10.1080/00380237.2007.10571316

Blomberg, T.G., Bales, W.D. and Piquero, A.R. (2012). Is educational achievement a turning point for incarcerated delinquents across race and sex? Journal of Youth and Adolescence, 41, pp. 202-216. https://doi.org/10.1007/s10964-011-9680-4

Boutwell, B.B. and Beaver, K.M. (2010). The role of broken homes in the development of self-control: A propensity score matching approach. Journal of Criminal Justice, 38(4), pp. 489-495. https://doi.org/10.1016/j.jcrimjus.2010.04.018

Bush, C.A., Mullis, R.L. and Mullis, A.K. (2000). Differences in empathy between offender and non-offender youth. Journal of Youth and Adolescence, 29, pp. 467-478. https://doi.org/10.1023/A:1005162526769

Cairns, R.B. and Cairns, B.D. (1994). Lifelines and risks: Pathways of youth in our time. New York: Cambridge.

Carlsson, C. (2012). Using 'turning points' to understand processes of change in offending. British Journal of Criminology, 52, pp. 1-16. https://doi.org/10.1093/bjc/azr062

Centers for Disease Control and Prevention. (2015). Injury prevention and control: Adverse Childhood Experiences (ACE) Study. Available at: http://www.cdc.gov/violenceprevention/acestudy/

Elder, G.H. (1985). Perspectives on the life course. In G.H. Elder (Ed.), Life course dynamics: Trajectories and transitions, 1968-1980. Ithaca, New York: Cornell University Press, pp. 3-20.

Elder, G.H., Johnson, M.K. and Crosnoe, R. (2003). The emergency and development of life course theory. In J.T. Mortimer and M.J. Shanahan (Eds.), Handbook of the life course. New York: Kluwer Academic/Plenum Publishers, pp. 3-19. https://doi.org/10.1007/978-0-306-48247-2_1

Evans, G.W., Li, D. and Whipple, S.S. (2013). Cumulative risk and child development. Psychological Bulletin, 139, pp. 1342-1396. https://doi.org/10.1037/a0031808

Fanti, K.A. and Henrich, C.C. (2010). Trajectories of pure and co-occurring internalizing and externalizing problems from age 2 to age 12: findings from the national institute of child health and human development study of early child care. Developmental Psychology, 46, pp. 1159-1175. https://doi.org/10.1037/a0020659

Farrington, D.P., Ttofi, M.M. and Piquero, A.R. (2016). Risk, promotive, and protective factors in youth offending: Results from the Cambridge study in delinquent development. Journal of Criminal Justice, 45, pp. 63-70. https://doi.org/10.1016/j.jcrimjus.2016.02.014

Farrington, D.P. and Welsh, B.C. (2007). Saving children from a life of crime: Early risk factors and effective interventions. Oxford: Oxford University Press.

Felitti, V.J., Anda, R.F., Nordenberg, D., Williamson, D.F., Spitz, A.M. and Edwards, V. (1998). Relationship of childhood abuse and household dysfunction to many of the leading causes of death in adults: The Adverse Childhood Experiences (ACE) Study. American Journal of Preventive Medicine, 14, pp. 245-258. https://doi.org/10.1016/S0749-3797(98)00017-8

Ford, J. (2005). Substance use, the social bond, and delinquency. Sociological Inquiry, 75, pp. 109-128. https://doi.org/10.1111/j.1475-682X.2005.00114.x

Ford, J. and Schroeder, R.D. (2011). Higher education and criminal offending over the life course. Sociological Spectrum, 31, pp. 32-58. https:// doi.org/10.1080/02732173.2011.525695 
Foster, H. and Hagan, J. (2007). Incarceration and intergenerational social exclusion. Social Problems, 54, pp. 399433. https:// doi.org/10.1525/sp.2007.54.4.399

Fox, K.J. (2016). Civic commitment: Promoting desistance through community integration. Punishment and Society, 18, pp. 68-94. https:// doi.org/10.1177/1462474515623102

Garbarino, J. (1995). Raising children in a socially toxic environment. San Francisco, CA: Jossey-Bass.

Garbarino, J. (1999). Lost boys: Why our sons turn violent and how we can save them. New York: The Free Press.

Garnier, H.E. and Stein, J.A. (2002). An 18-year model of family and peer effects on adolescent drug use and delinquency. Journal of Youth and Adolescence, 31, pp. 45-56. https://doi.org/10.1023/A:1014085016511

Gilgun, J.F. (1996). Human development and adversity in ecological perspective, part 1: A conceptual framework. Families in Society, 77, pp. 395-402. https://doi.org/10.1606/1044-3894.956

Hawdon, J. (2004). Drug use in middle school: Assessing attitudinal and behavioral predictors. Free Inquiry in Creative Sociology, 32, pp. 59-71.

Higgins, G.E., Piquero, N.L. and Piquero, A.R. (2011). General strain theory, peer rejection, and delinquency/crime. Youth and Society, 43, pp. 1272-1297. https://doi.org/10.1177/0044118X10382032

Hoffman, J.P. and Dufur, M.J. (2008). Family and school effects on delinquency: Substitutes or complements? Sociological Perspectives, 51, pp. 29-62. https://doi.org/10.1525/sop.2008.51.1.29

Holligan, C. and Deuchar, R. (2015). What does it mean to be a man? Psychosocial undercurrents in the voices of incarcerated (violent) Scottish teenage offenders. Criminology and Criminal Justice, 15, pp. 361-377. https://doi.org/10.1177/1748895814545407

Hutchison, J. (2009). Mental illness, poverty, and crime. Child and Family, 12, pp. 21-25.

Ireland, T.O. and Smith, C.A. (2009). Living in partner-violent families: Developmental links to antisocial behavior and relationship violence. Joumal of Youth and Adolescence, 38(3), pp. 323-339. https://doi.org/10.1007/s10964008-9347-y

Kierkus, C.A. and Baer, D. (2003). Does the relationship between family structure and delinquency vary according to circumstances? An investigation of interaction effects. Canadian Journal of Criminology and Criminal Justice, 45, pp. 405-429. https://doi.org/10.3138/cjccj.45.4.405

Klevens, J., Roca, J., Restrepo, O. and Martinez, A. (2001). Risk factors for adult male criminality in Colombia. Criminal Behaviour and Mental Health, 11(2), pp. 73-85. https://doi.org/10.1002/cbm.372

Laub, J.H. and Sampson, R.J. (2003). Shared beginnings, divergent lives: Delinquent boys to age 70. Cambridge, MA: Harvard University Press.

Laurens, K.R., Tzoumakis, S., Kariuki, M., Green, M.J., Hamde, M., Harris, F., Carr, V. J. and Dean, K. (2017). Pervasive influence of maternal and paternal criminal offending on early child development: a population data linkage study. Psychological Medicine, 47, pp. 889-901. https://doi.org/10.1017/S0033291716003007

Maggi, S., Irwin, L.J., Siddiqi, A. and Hertzman, C. (2010). The social determinants of early child development: An overview. Journal of Paediatrics and Child Health, 46, pp. 627-635. https://doi.org/10.1111/j.14401754.2010.01817.x

Maldonado-Molina, M.M., Piquero, A.R., Jennings, W.G., Bird, H. and Canino, G. (2009). Trajectories of delinquency among Puerto Rican children and adolescents at two sites. Journal of Research in Crime and Delinquency, 46(2), pp. 144-181. https://doi.org/10.1177/0022427808330866

Mendel, W.E., Tomasello, N.M. and Nochajski, T.H. (2012). Building evidence for a prevention-focused education program targeting parents of infants and toddlers. Journal of Family Social Work, 15, pp. 272-287. https://doi.org/10.1080/10522158.2012.678034

Minh, A., Matheson, F.I., Dauod, N., Hamilton-Wright, S., Pedersen, C., Borenstein, H. and O'Campo, P. (2013). Linking childhood and adult criminality: Using a life course frame-work to examine childhood abuse and neglect, substance use and adult partner violence. International Journal of Environmental Research and Public Health, 10, pp. 5470-5489. https://doi.org/10.3390/ijerph10115470

Moffitt, T.E. (1993). Adolescence-limited and life-course-persistent antisocial behavior: A developmental taxonomy. Psychological Review, 100, pp. 674-701. https://doi.org/10.1037/0033-295X.100.4.674

Moffitt, T.E., Arseneault, L., Belsky, D., Dickson, N. Hancox, R.J., Harraington, H.L., Houts, R., Poulton, R., Roberts, B.W., Ross, S., Sears, M.R., Thomson, W.M. and Caspi, A. (2011). A gradient of childhood self-control predicts bealth, wealth, and public safety. Proceedings of the National Academy of Sciences, 108, pp. 2693-2698. https://doi.org/10.1073/pnas.1010076108

Murray, J., Irving, B., Farrington, D.P., Colman, I. and Boxsom, C. (2010). Very early predictors of conduct problems and crime: Results from a national cohort study. Journal of Child Psychology and Psychiatry and Allied Disciplines, 51, pp. 1198-1207. https://doi.org/10.1111/j.1469-7610.2010.02287.x

Nelson, D.A., Hart, C.H., Yang, C., Olsen, J.A. and Jin, S. (2006). Aversive parenting in China: Associations with child physical and relational aggression. Child Development, 77(3), pp. 554-572. https://doi.org/10.1111/j.14678624.2006.00890.x 
Park, A., Smith, C. and Ireland, T. (2012). Equivalent harm? The relative roles of maltreatment and exposure to intimate partner violence in antisocial outcomes for young adults. Children and Youth Services Review, 34, pp. 962972. https://doi.org/10.1016/j.childyouth.2012.01.029

Patt, Y.F. (2010). Influences of mothering and neighborhood on children's behavioral outcomes. Children, Youth, and Environments, 20(1), pp. 91-122.

Payne, B.K., Gainey, R.R. and Carey, C.S. (2005). All in the family: Gender, family crimes, and later criminality. Women and Criminal Justice, 16(4), pp. 73-89. https://doi.org/10.1300/J012v16n04_04

Pennsylvania Partnerships for Children. (1998). Infancy and early childhood: Opportunities and risks for Pennsylvania and its children: A special report. Harrisburg, PA: Pennsylvania Kids Count Partnership.

Piquero, A.R., Farrington, D.P., Nagin, D.S. and Moffitt, T.E. (2012). Trajectories of offending and their relation to life failure in middle age: Findings from the Cambridge study in delinquent development. Journal of Research in Crime and Delinquency, 47, pp. 151-173. https://doi.org/10.1177/0022427809357713

Piquero, A.R. and Mazerolle, P. (Eds.) (2001). Life-course criminology. Belmont, CA: Wadsworth.

Reavis, J.A., Looman, J., Franco, K.A. and Rojas, B. (2013). Adverse childhood experiences and adult criminality. The Permanente Journal, 17(2), pp. 44-48. https:// doi.org/10.7812/TPP/12-072

Rocque, M. (2015). The lost concept: The (re)emerging link between maturation and desistance. Criminology and Criminal Justice, 15, pp. 340-360. https:/ / doi.org/10.1177/1748895814547710

Sabates, R., and Dex, S. (2015). The impact of multiple risk factors on young children's cognitive and behavioural development. Children and Society, 29(2), pp. 96-108. https:// doi.org/10.1111/chso.12024

Sampson, R.J. and Laub, J.H. (1992). Crime and deviance in the life course. Annual Review of Sociology, 18, pp. 6384. https://doi.org/10.1146/annurev.so.18.080192.000431

Sampson, R.J. and Laub, J.H. (1993). Crime in the making: Pathways and turning points through life. Cambridge, MA: Cambridge University Press.

Sampson, R.J. and Laub, J.H. (1997). A life-course theory of cumulative disadvantage and the stability of delinquency. In T.P. Thornberry (Ed.), Developmental theories of delinquency. New Brunswick, NJ: Transaction, pp. 133-162.

Sampson, R.J. and Laub, J.H. (2003). Life-course desisters? Trajectories of crime among delinquent boys followed to age 70. Criminology, 41, pp. 555-592. https://doi.org/10.1111/j.1745-9125.2003.tb00997.x

Simons, L.G. and Conger, R.D. (2007). Linking mother-father differences in parenting to a typology of family parenting styles and adolescent outcomes. Journal of Family Issues, 28(2), pp. 212-241. https://doi.org/10.1177/0192513X06294593

Staff, J., Whichard, C., Siennick, S.E. and Maggs, J. (2015). Early life risks, antisocial tendencies, and preteen delinquency. Criminology, 53, pp. 677-701. https://doi.org/10.1111/1745-9125.12093

Stevenson, S.T., Hall, G. and Innes, J.M. (2004). Rationalizing criminal behavior: The influence of criminal sentiments on socio-moral development in violent offender and nonoffenders. International Journal of Offender Therapy Comparative Criminology, 48, pp. 161-174. https:// doi.org/10.1177/0306624X03258483

Sullivan, C., and Newsome, J. (2015). Psychosocial and genetic risk markers for longitudinal trends in delinquency: an empirical assessment and practical discussion. Criminal Justice Studies, 28(1), pp. 61-83.

Topitzes, J., Mersky, J. and Reynolds, A. (2011). Child maltreatment and offending behavior: Gender-specific effects and pathways. Criminal Justice and Behavior, 38, pp. 492-510. https:// doi.org/10.1177/0093854811398578

Tourangeau, R. and Yan, T. (2007). Sensitive survey questions. Psychological Bulletin, 133(5), pp. 859-883. https://doi.org/10.1037/0033-2909.133.5.859

Tremblay, R.E. (2013). Development of antisocial behavior during childhood. In C.L. Gibson and M.D. Krohn (Eds.), Handbook of life-course criminology: Emerging trends and directions for future research. New York: Springer, pp. 319. https://doi.org/10.1007/978-1-4614-5113-6_1

Vogel, M. and Messner, S.F. (2012). Social correlates of delinquency for youth in need of mental health services: Examining the scope conditions of criminological theories. Justice Quarterly, 29(4), pp. 546-572. https://doi.org/10.1080/07418825.2011.582879

Werner, E. (2005). Resiliency and recovery: Findings from the Kauai longitudinal study. Focal Point: Research, Policy, and Practice in Children's Mental Health, 19, pp. 11-14.

Widom, C.S., Schuck, A.M. and White, H.R. (2006). An examination of pathways from childhood victimization to violence: The role of early aggression and problematic alcohol use. Violence and Victims, 21(6), pp. 675-690. https://doi.org/10.1891/0886-6708.21.6.675

Widom, C.S. and White, H.R. (1997). Problem behaviours in abused and neglected children grown up: Prevalence and co-occurrence of substance abuse, crime, and violence. Criminal Behaviour and Mental Health, 7, pp. 287-310. https://doi.org/10.1002/cbm.191 
Wolff, K.T., Baglivio, M.T. and Piquero, A.R. (2017). The relationship between adverse childhood experiences and recidivism in a sample of juvenile offenders in community-based treatment. International Journal of Offender Therapy and Comparative Criminology, 61(11), pp. 1210-1242. https:/ / doi.org/10.1177/0306624X15613992

Yampolskaya, S., Armstrong, M.I. and McNeish, R. (2011). Children placed in out-of-home care: Risk factors for involvement with the juvenile justice system. Violence and Victims, 26(2), pp. $231-245$. https://doi.org/10.1891/0886-6708.26.2.231

Young, M.E. (2015). Early child development: A framework for collaboration. International Journal of Child Care and Education Policy, 4, pp. 25-32. https://doi.org/10.1007/2288-6729-4-2-25 